\section{PELATIHAN \\ PEMBUATAN LAMPU PENERANGAN JALAN SWAENERGI DI DUSUN KECAPI, PADANG CERMIN}

FX. Arinto Setyawan*, Umi Murdika, Helmy Fitriawan, Afri Yudamson

Teknik Elektro, Universitas Lampung

\begin{abstract}
Abstrak
Lampu penerangan jalan merupakan salah satu fasilitas utama yang dibutuhkan suatu daerah. Sayangnya karena keterbatasan energi listrik yang dihasilkan, tidak semua daerah mendapatkan fasilitas ini. Pengabdian ini bertujuan membagi pengetahuan mengenai pembangkit listrik skala mikro bertenaga surya (Swaenergi) untuk diaplikasikan untuk penerangan jalan. Pada pengabdian ini dilakukan pelatihan cara merangkai komponenkomponen yang dibutuhkan dalam lampu jalan swaenergi yang terdiri dari panel surya, Battery Control Regulator (BCR), Aki, dan lampu DC serta cara perawatannya. Materi pelatihan berisikan mengenai pembangkit listrik skala mikro bertenaga surya, komponen yang diperlukan dalam pembuatan lampu penerangan jalan swaenergi, cara perawatan komponen agar lampu penerangan ini lebih awet, dan cara pembuatan atau perangkaian lampu penerangan jalan swaenergi. Keberhasilan pelatihan diukur berdasarkan peningkatan nilai pre-test dengan post-test. Pada pengabdian ini terjadi peningkatan pengetahuan peserta mengenai penggunaan pembangkit listrik skala mikro bertenaga surya untuk diaplikasikan pada lampu penerangan jalan. Peningkatan pengetahuan diindikasikan dari peningkatan nilai pre-test sebesar 4,07 menjadi 9,07 pada post-test. Perakitan lampu penerangan jalan swaenergi ini dibantu oleh mahasiswa teknik elektro angkatan 2016 dan 2017 dan berhasil dipasang di dusun Kecapi, Padang Cermin, Lampung.
\end{abstract}

Kata Kunci: Battery Control Regulator; Panel Surya; Penerangan Jalan; Swaenergi

\begin{abstract}
Street lighting is one of the main facilities needed by an area. Unfortunately, due to the limited electrical energy produced, not all regions have this facility. This community service aims to share knowledge about the microscale solar-powered power plants to be applied for street lighting. In this community service, training was conducted on how to assemble the components needed in a self-energized street light consisting of solar panels, $B C R$, batteries, and $D C$ lamps and how to maintain them. The training material contains solar-powered micro-scale power plants, the components needed in making self-energized street lighting, how to care for components so that these lamps last longer, and how to manufacture or assemble selfenergy street lighting. The training success's effectiveness is measured based on the increase in the pre-test score with the post-test. In this community service, there was an increase in the participants' knowledge about using micro-scale solar-powered power plants to be applied to street lighting. The increase in knowledge is indicated by the increase in the pre-test score of 4.07 to 9.07 in the post-test. This self-energy street lighting assembly was assisted by electrical engineering student's class 2016 and 2017 and was successfully installed in Kecapi hamlet, Padang Cermin, Lampung.
\end{abstract}

Keywords: Battery Control Regulator; Solar Panel; Street Lighting; SelfEnergized

\section{PENDAHULUAN}

Kecapi merupakan nama salah satu dusun di Kecamatan Padang Cermin, Kabupaten Pesawaran. Lokasi ini berjarak sekitar $40 \mathrm{Km}$ dari Bandar Lampung ke arah barat daya. Potensi pertanian daerah ini adalah Padi dan jagung. Sedangkan potensi industri adalah industri kerajinan rakyat, industri makanan, penggilingan padi, dan tobong bata. Sedangkan daerah pesisir memiliki potensi berupa hasil laut dan pengolahannya selain sektor pariwisata berupa pantai (Altab et al., 2018). Kabupaten Pesawaran memiliki banyak ekowisata 
di sepanjang pantai misalnya hutan Mangrove (Sari et al., 2015).

Potensi wisata berupa pantai di sepanjang jalan sangat membutuhkan penerangan jalan saat malam hari. Sayangnya daerah ini sering mengalami pemadaman listrik karena kurangnya pasokan listrik. Oleh karena itu diperlukan lampu jalan yang tidak terpengaruh oleh pasokan listrik dari Perusahaan Listrik Negara (PLN). Salah satu sumber energi yang dapat dikonversi menjadi listrik yang keberadaannya melimpah adalah sinar matahari (Widodo \& Andrasto, 2010). Oleh karena itu perlu dilakukan transfer teknologi berupa pembuatan lampu jalan bertenaga surya atau Swaenergi.

Lampu jalan bertenaga surya telah banyak dipergunakan terutama di daerah perkotaan. Dari penelitian sebelumnya, pada penerangan lampu jalan menggunakan lampu dc 12 volt, panel surya $50 \mathrm{Wp}$, charge control $10 \mathrm{~A}$, battery 65 Ah dapat digunakan selama 12 jam (Anhar et al., 2019). Tren dimasa mendatang lampu ini akan banyak menggantikan lampu jalan yang menggunakan listrik dari transmisi PLN karena penerangan jalan menggunakan sumber PLN memiliki konsumsi daya yang lebih besar jika dibandingkan dengan yang bersumber dari PLTS (Sihombing \& Kasim, 2013). Hal ini dapat membuka peluang usaha pembuatan lampu jalan swaenergi yang dapat dilakukan oleh para pemuda di daerah Padang Cermin.

Lampu penerangan jalan swaenergi (bertenaga surya) memiliki keunggulan dibanding lampu penerangan jalan menggunakan sumber listrik PLN yang didapat dari batu bara atau fosil (Sukmajati \& Hafidz, 2015). Keunggulannya antara lain adalah ramah lingkungan, sumber energi yang dibutuhkan tersedia di alam tanpa memerlukan biaya, hampir tanpa perawatan, tidak merusak jaringan listrik yang telah ada, dan dapat dipindahkan dengan mudah. Kekurangan lampu penerangan jalan swaenergi ini adalah biaya awal yang cukup mahal.

Pada pengabdian ini digunakan lampu LED DC sebagai sumber cahayanya. Pemakaian lampu LED DC ini memiliki keunggulan yaitu tidak memerlukan inverter yang digunakan untuk merubah arus searah menjadi arus bolak-balik, umur LED cukup lama dapat mencapai 50.000 jam, lampu LED cukup ramah lingkungan, tidak menghasilkan UV sehingga tidak panas, dan relatif murah harga lampunya (Faridha \& Yusuf Saputra, 2016). Pemakaian lampu LED DC ini mendukung pemanfaatan PLTS tanpa inverter (Sitompul et al., 2019).

Kegiatan pengabdian ini bertujuan memberikan pelatihan cara merangkai lampu penerangan jalan swaenergi dan menerangkan peralatanperalatan apa saja yang diperlukan, cara perawatan, dan cara menentukan besarnya daya lampu yang dapat dipasang (Effendi \& Aldifian, 2013). Kegiatan pengabdian ini diharapkan mampu meningkatkan kemampuan masyarakat dalam membuat dan merangkai lampu jalan swaenergi. Melalui kegiatan ini diharapkan masyarakat akan merasakan secara langsung keberadaan Universitas Lampung di dalam mendorong tingkat kesejahteraan masyarakat setempat dengan cara berbagi pengetahuan dari hasil penelitian yang ada di Universitas Lampung.

\section{METODE PELAKSANAAN}

Khalayak sasaran dari kegiatan pengabdian ini adalah pemuda dusun Kecapi dan guru-guru MTs Matla'ul Anwar agar mereka memiliki pengetahuan cara pembuatan lampu penerangan jalan swaenergi (bertenaga surya). Prosedur pelaksanaan pengabdian ini terdiri dari 3 tahap, yaitu tahap persiapan, tahap pelaksanaan, dan tahap evaluasi.

Tahap persiapan yang dilakukan adalah survey lapangan tempat pengabdian dilaksanakan dan penyiapan alat-alat pengabdian yang dibutuhkan. Survey dilakukan untuk mengetahui kebutuhan yang diperlukan oleh masyarakat tempat pengabdian dilaksanakan dan penetapan waktu pengabdian. Pengabdian dilaksanakan pada tanggal 27 Agustus 2020 di dusun Kecapi, Padang Cermin, Kab. Pesawaran, Lampung dengan peserta pemuda dan beberapa guru MTs Matla'ul Anwar. Setelah tema pengabdian ditentukan maka dilakukan penyiapan alat dan bahan yang dibutuhkan. Alat dan bahan yang diperlukan antara lain panel surya, BCR, Aki, lampu DC, tiang lampu, kotak aki, bor listrik, kunci pas, beberapa mur dan baut.

Tahap pelaksanaan dilakukan dengan pemberian materi mengenai lampu penerangan jalan swaenergi bertenaga surya. Pemateri pengabdian dilakukan oleh dosen Program Studi Teknik Elektro Universitas Lampung dibantu mahasiswa untuk praktek perakitan dan pemasangan peralatan.

Tahap evaluasi dilaksanakan untuk mengetahui keberhasilan pelaksanaan pengabdian. Tahap ini dilakukan dengan cara pemberian pretest dan post-test mengenai materi lampu penerangan swaenergi yang dibuat. Peningkatan nilai post-test dari nilai pre-test dianggap sebagai keberhasilan penyampaian materi mengenai lampu penerangan jalan swaenergi.

\section{PEMBAHASAN}

Pengabdian ini dilaksanakan pada masa pandemic Covid-19. Oleh karena itu, pengabdian dilaksanakan dengan mematuhi prosedur protokol kesehatan yaitu menghindari kerumunan berlebih dan penggunaan masker bagi peserta dan pemateri. Pelatihan dilakukan pada dua tempat 
yang berbeda yaitu di Masjid Jamiatul Anwar dan di MTs Matla'ul Anwar hal ini untuk menghindari kerumunan massa yang berlebih. Kegiatan pelatihan yang diadakan di Masjid Jamiatul Anwar (Gambar 1) dan kegiatan pelatihan yang diadakan di MTs Matla'ul Anwar (Gambar 2).

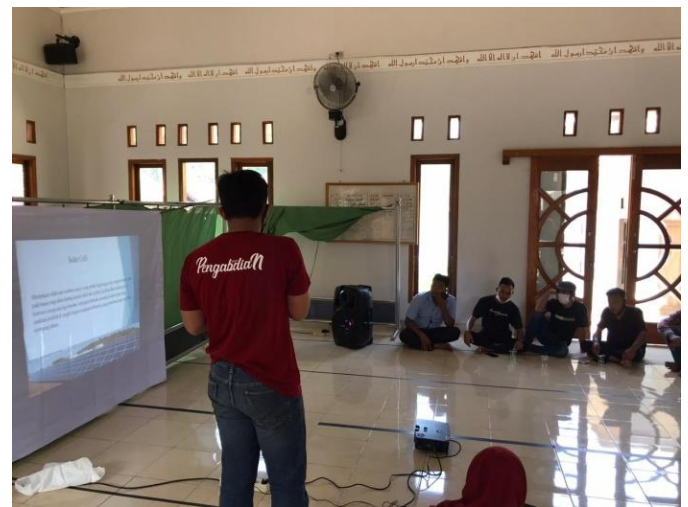

Gambar 1. Pelatihan diadakan di Masjid Jamiatul Anwar

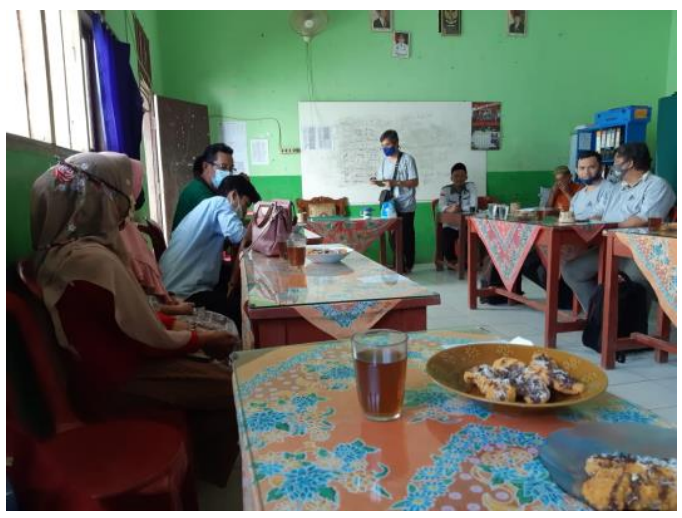

Gambar 2. Pelatihan diadakan di MTs Matla'ul Anwar

Bahan (komponen) yang digunakan dalam pengabdian ini adalah panel surya, BCR, aki, lampu LED DC 30W, kabel, kotak aki, tiang lampu, dan beberapa mur dan baut. Beberapa komponen yang digunakan diperlihatkan pada Gambar 3. Tahap pelaksanaan dalam kegiatan ini adalah pemberian materi oleh tim pengabdian tentang komponen-komponen yang digunakan, tata cara pengkabelannya, dan tata cara perawatan kepada pemuda dan guru MTs yang hadir. Penjelasan ini dilakukan oleh Dosen Tim Pengabdian dibantu oleh mahasiswa Teknik Elektro Unila. Materi pengabdian disusun oleh tim dosen dan presentasi dibantu oleh mahasiswa teknik Elektro.

Materi pengabdian terdiri dari pembangkit listrik tenaga surya skala mikro (Julisman et al., 2017), komponen lampu penerangan jalan swaenergi, tata cara perawatan komponen lampu penerangan (Sutrisno et al., 2019), dan perancangan lampu penerangan (Hikmawan \& Suprayitno, 2018). Setelah dilakukan pemberian materi secara presentasi maka dilakukan praktik perakitan. Rancangan lampu penerangan jalan swaenergi diperlihatkan pada Gambar 4.

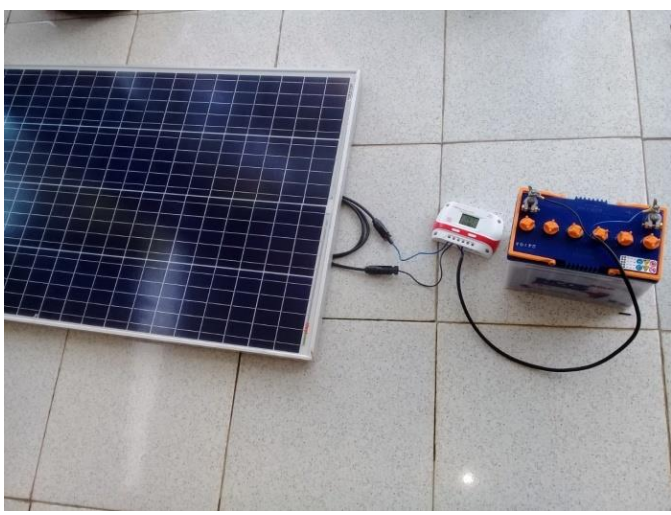

Gambar 3. Komponen utama lampu penerangan jalan swaenergi

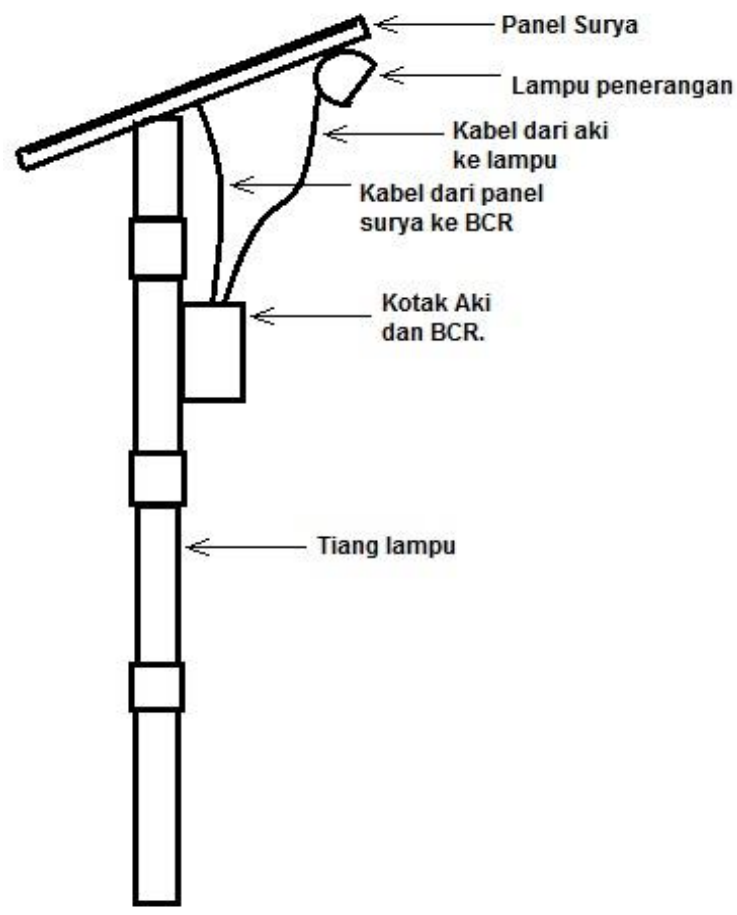

Gambar 4. Rancangan lampu penerangan jalan swaenergi

Perakitan dan pemasangan lampu penerangan jalan swaenergi dilakukan oleh mahasiswa dengan bimbingan dosen tim pengabdian. Proses perakitan dan pemasangan lampu pe- 
nerangan jalan dibantu oleh mahasiswa Teknik Elektro angkatan 2016 dan 2017 (Gambar 5).

Prosedur perakitan lampu penerangan jalan swaenergi dilakukan melalui beberapa tahap. Tahap pertama adalah pengetesan bahan yaitu pengukuran adanya tegangan yang dihasilkan oleh panel surya saat mendapat sinar matahari. Setelah panel surya diketahui dalam kondisi baik maka panel surya dihubungkan dengan BCR dan aki. Dilakukan pengukuran tegangan dari $B C R$ ke aki untuk memastikan BCR dapat mengisi aki dengan baik. Selanjutnya lampu dihubungkan ke BCR untuk mengetes apakah lampu dapat menyala atau tidak. Jika menyala maka dapat dilanjutkan ke tahap berikutnya.

Tahap kedua adalah pemasangan lampu penerangan jalan pada tiang lampu. Setelah semua bahan diketahui dalam kondisi baik maka dilakukan perakitan pada tiang lampu. Pada tahap ini semua peralatan dipasang pada tempat yang disediakan. Setelah itu semua peralatan yang telah terpasang dihubungkan menggunakan kabel. Kemudian mencoba menyalakan lampu DC yang digunakan, jika lampu dapat menyala maka tiang lampu dapat dipasang pada tempat yang diinginkan.

Tahap ketiga adalah pemasangan tiang lampu pada tempat yang disediakan. Pesangan dapat dilakukan dengan cara menanam tiang lampu menggunakan semen atau meletakkan tiang pada tembok yang ada menggunakan klem logam. Tiang lampu sebaiknya diletakkan pada daerah yang membutuhkan penerangan jalan dan pada lokasi dimana panel surya tidak terhalang memperoleh sinar matahari.

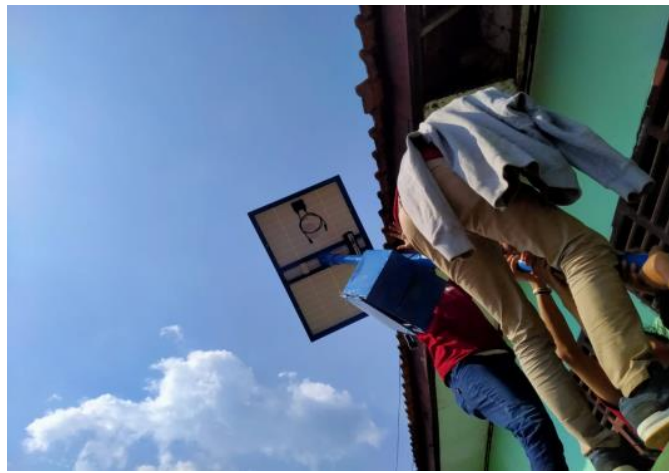

Gambar 5. Proses pemasangan lampu penerangan jalan swaenergi

Pengetahuan mengenai tata cara perawatan lampu penerangan jalan diberikan melalui pemberian materi cara merawat tiap komponen yang ada. Selain itu, peralatan akan bertahan lama jika bahan yang digunakan sesuai kebutuhan yang diinginkan. Oleh karena itu diperlukan pengetahuan cara menghitung kebutuhan bahan yang diperlukan.

Materi pelatihan yang diberikan juga menyangkut perhitungan-perhitungan yang diperlukan untuk menentukan kapasitas komponen yang dibutuhkan. Pada pengabdian ini digunakan panel surya 100WP artinya 100 Watt merupakan nilai daya tertinggi yang dapat dihasilkan oleh panel surya atau daya yang dihasilkan modul surya pada titik daya maksimum (Hariansyah, 2009).

Dengan asumsi bahwa panel surya 100WP akan menghasilkan energi listrik sebesar 500W jam maka perlu penyimpanan energi berupa aki $45 \mathrm{AH}$ yang memiliki tegangan keluaran sebesar $12 \mathrm{~V}$ atau sekitar $540 \mathrm{WH}$. Agar panel surya dapat mengisi aki maka diperlukan peralatan berupa baterai control regulator yang dapat juga digunakan untuk mengatur kapan lampu menyala atau mati. Aki akan awet jika penggunaannya tidak melebihi $70 \%$ dari kapasitas energy maksimumnya atau sekitar 378 WH. Jika diinginkan lampu dapat menyala selama 12 jam maka lampu yang dapat dipasang adalah $30 \mathrm{~W}$. Pemberian materi ini bertujuan agar peserta pelatihan dapat menghitung kebutuhan komponen bila untuk keperluan lainnya.

Pengujian lampu penerangan jalan swaenergi dilakukan dengan melihat apakah lampu dapat menyala sesuai waktu atau kondisi yang diinginkan. Lampu dapat diset menyala dalam satuan waktu yaitu jam (misalnya 10 jam) dan lampu dapat diset menyala berdasarkan kondisi lingkungan yaitu jika kondisi sudah gelap maka akan menyala dan mati jika sudah terang. Pengesetan ini dilakukan melalui peralatan BCR yang digunakan.

Keberhasilan pelatihan pada pengabdian ini diukur menggunakan hasil pre-test dan post-test yang diberikan sebelum dan setelah pelatihan. Metode pemberian Pre-test dan Post-test dalam pelatihan atau pembelajaran terbukti mempunyai pengaruh yang berarti terhadap hasil belajar (Effendy, 2016). Peningkatan pengetahuan didapatkan dari peningkatan nilai pre-test yang diukur dari nilai post-test mereka. Pertanyaan soal pre-test sama dengan pertanyaan pada soal post-test. Penilaian dilakukan dengan merata-rata seluruh nilai pre-test dan post-test seperti dilakukan pada penelitian-penelitian sebelumnya (Damayanti et al., 2017).

Kegiatan pengabdian ini telah berhasil menyerahkan lampu penerangan jalan swaenergi kepada masyarakat dusun Kecapi di Padang Cermin. Serah terima lampu penerangan jalan swaenergi kepada masyarakat dusun Kecapi yang diwakili oleh salah satu guru MTs agar dapat dimanfaatkan untuk kepentingan masyarakat dusun Kecapi (Gambar 6). 


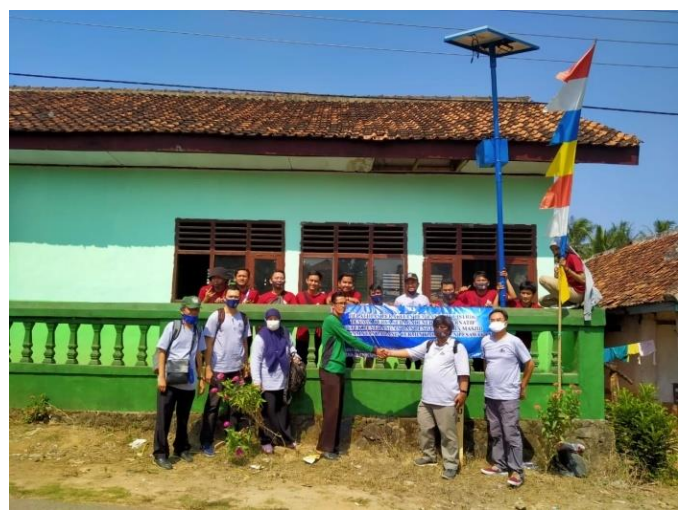

Gambar 6. Proses serah terima lampu penerangan jalan swaenergi kepada perwakilan masyarakat Dusun Kecapi di Padang Cermin

Nilai hasil pre-test didapatkan rata-rata nilai peserta yaitu 4,07. Pre-test dilakukan sebelum dilaksanakan pemberian materi mengenai lampu penerangan jalan swaenergi. Peserta pelatihan umumnya tidak mengetahui komponen apa saja yang diperlukan dalam pembuatan lampu penerangan jalan swaenergi dan fungsi komponen tersebut. Setelah dilakukan pemberian materi nilai hasil post-test mencapai 9,07. Artinya setelah dilakukan pemberian materi pengetahuan peserta menjadi lebih baik. Pre-test dan post-test berisikan soal-soal yang sama yang terdiri 10 soal mengenai lampu penerangan jalan bertenaga surya.

\section{KESIMPULAN}

Kegiatan pengabdian kepada masyarakat telah dilaksanakan dengan menyerah terimakan hasil perancangan berupa lampu penerangan jalan swaenergi kepada masyarakat dusun Kecapi, padang Cermin. Kegiatan pelatihan yang diadakan dari pengabdian ini berhasil meningkatkan pengetahuan masyarakat akan pembangkit listrik skala mikro bertenaga surya dengan ditandai peningkatan nilai pre-test sebesar 4,07 menjadi 9,07 nilai post-test. Kegiatan pengabdian selanjutnya dapat mengkombinasikan pembangkit listrik tenaga surya ini untuk keperluan lainnya yang berguna bagi masyarakat, misalnya untuk kebutuhan listrik perumahan dan fasilitas lainnya.

\section{UCAPAN TERIMA KASIH}

Ucapan terima kasih disampaikan kepada Universitas Lampung yang telah membiayai kegiatan pengabdian ini melalui hibah pengabdian senior DIPA BLU UNILA tahun anggaran 2020.

\section{DAFTAR PUSTAKA}

Altab, M., Faida, L. R. W., \& Fandeli, C. (2018). Pengembangan Ekowisata Bahari Di Kecamatan Padang Cermin Kabupaten Pesawaran Provinsi
Lampung (Marine Ecotourism Development in Padang Cermin, Pesawaran, Lampung). Jurnal Manusia Dan Lingkungan, 25(2), 53-59. https://doi.org/https://doi.org/10.22146/jml.23044

Anhar, W., Akbar, S., Basri, B., Laksito, A., \& Huda, N. (2019). Penerapan Lampu Penerangan Jalan Umum Berbasis Solar System Di RT. 50 Kelurahan SepingganBalikpapan. KACANEGARA Jurnal Pengabdian Pada Masyarakat, 2(2), 67-74. https://doi.org/10.28989/kacanegara.v2i2.433

Damayanti, N. A., Pusparini, M., Djannatun, T., \& Ferlianti, R. (2017). Metode Pre-Test Dan Post-Test Sebagai Salah Satu Alat Ukur Keberhasilan Kegiatan Penyuluhan Kesehatan Tentang Tuberkulosis Di Kelurahan Utan Panjang, Jakarta Pusat. Prosiding SNaPP: Kesehatan (Kedokteran, Kebidanan, Keperawatan, Farmasi, Psikologi), 3(1), 144-150. http://proceeding.unisba.ac.id/index.php/kesehata n/article/view/1131

Effendi, A., \& Aldifian, A. (2013). Perencanaan Penerangan Jalan Umum Jalan Lingkar Utara Kota Solok. Jurnal Teknik Elektro, 1(2), 23-32. https://ejournal.itp.ac.id/index.php/telektro/article/v iew/16

Effendy, I. (2016). Pengaruh pemberian pre-test dan posttest terhadap hasil belajar mata diklat hdw. dev. 100.2. a pada siswa smk negeri 2 lubuk basung. VOLT: Jurnal IImiah Pendidikan Teknik Elektro, 1(2), 81-88.

https://jurnal.untirta.ac.id/index.php/VOLT/article/vi ew/2873

Faridha, M., \& Yusuf Saputra, M. D. (2016). Analisa Pemakaian Daya Lampu Led Pada Rumah Tipe 36. Jurnal Teknologi Elektro, 7(3), 193-198. https://doi.org/10.22441/jte.v7i3.898

Hariansyah, M. (2009). Perencanaan Pembangkit Listrik Tenaga Surya Pada Rumah Tangga Kapasitas 500 W, 220 V. Jurnal Sains Dan Teknologi Elektro, Elektriese, 2(1),

$1-17$. https://www.scribd.com/document/457631093/Elektr ieseVol2N01Oktober2009-pdf

Hikmawan, S. R., \& Suprayitno, E. A. (2018). Rancang Bangun Lampu Penerangan Jalan Umum (Pju) Menggunakan Solar Panel Berbasis Android. Elinvo (Electronics, Informatics, and Vocational Education), 3(1), 9-17. https://doi.org/10.21831/elinvo.v3i1.15343

Julisman, A., Sara, I. D., \& Siregar, R. H. (2017). Prototipe Pemanfaatan Panel Surya Sebagai Sumber Energi Pada Sistem Otomasi Stadion Bola. Jurnal Karya Ilmiah Teknik Elektro, 2(1), 35-42. http://erepository.unsyiah.ac.id/kitektro/article/view/6756

Sari, Y., Budi Yuwono, S., \& Rusita, R. (2015). Analisis Potensi Dan Daya Dukung Sepanjang Jalur Ekowisata Hutan Mangrove Di Pantai Sari Ringgung, Kabupaten Pesawaran, Lampung. Jurnal Sylva Lestari, 3(3), 3140. https://doi.org/10.23960/jsl3331-40

Sihombing, D. T. B., \& Kasim, K. (2013). Perencanaan Sistem Penerangan Jalan Umum Dan Taman Di Areal Kampus Usu Dengan Menggunakan Teknologi Tenaga Surya (Aplikasi Di Areal Pendopo Dan Lapangan Parkir). Departemen Teknik Elektro Fakultas Teknik Universitas Sumatera Utara. Singuda Ensikom, 3(3), 118-123. https://jurnal.usu.ac.id/index.php/singuda_ensikom/ 
article/view/2668/

Sitompul, D., Kumara, I. N. S., \& Partha, C. G. I. (2019) "Ketersediaan Peralatan Listrik Bercatu Daya DC Untuk Mendukung Pemanfaatan PLTS Tanpa Inverter Pada Rumah Tangga Urban. Jurnal SPEKTRUM, 6(3), 122-126.

https://ojs.unud.ac.id/index.php/spektrum/article/vi ew $/ 52825$

Sukmajati, S., \& Hafidz, M. (2015). Perancangan Dan Analisis Pembangkit Listrik Tenaga Surya Kapasitas 10 MW On Grid Di Yogyakarta. Energi \& Kelistrikan, 7(1), 49-63.

journal.id/energi/article/view/582
Sutrisno, S., Hidayat, S., Hariyanto, H., \& Suaedi, D. A. (2019). Perawatan Listrik Tenaga Surya Untuk Penerangan Jalan Desa Bagi Karangtaruna Desa Glanggang Kecamatan Pakisaji Malang. Jurnal Graha Pengabdian, 1(1), 10-17. http://journal2.um.ac.id/index.php/jgp/article/view/ 9957

Widodo, D. A., \& Andrasto, T. (2010). Pemberdayaan Energi Matahari Sebagai Energi Listrik Lampu Pengatur Lalu Lintas. Jurnal Teknik Elektro, 2(2), 133-136. https://journal.unnes.ac.id/nju/index.php/jte/article/ view/1553 